\title{
PEMANFAATAN LIMBAH CANGKANG KERANG BULU SEBAGAI ADSORBEN UNTUK MENJERAP LOGAM KADMIUM (II) DAN TIMBAL (II)
}

\author{
Akhmad Anugerah S, Iriany \\ Departemen Teknik Kimia, Fakultas Teknik, Universitas Sumatera Utara \\ Jl. Almamater Kampus USU Medan, 20155 Indonesia \\ Email: anerah_s@yahoo.com
}

\begin{abstract}
Abstrak
Adsorben cangkang kerang bulu dapat digunakan untuk mengadsorpsi ion logam berat seperti $\mathrm{Cd}(\mathrm{II})$ dan $\mathrm{Pb}$ (II). Hal ini terlihat dari hasil penelitian adsorben cangkang kerang bulu yang dibuat. Penelitian ini bertujuan untuk karakterisasi dari cangkang kerang bulu yang dibuat. Variabel dalam penelitian ini adalah suhu aktivasi dan konsentrasi larutan logam yang digunakan. Penelitian ini diawali dengan melakukan pengecilan ukuran cangkang kerang bulu menjadi seukuran 140 mesh, kemudian dilakukan aktivasi termal pada suhu $110^{\circ} \mathrm{C}, 500^{\circ} \mathrm{C}$ dan $800^{\circ} \mathrm{C}$ di dalam furnace. Selanjutnya adsorben yang dibuat dikarakterisasi menggunakan peralatan BET, diukur berat jenis, kadar air dan abu, serta kemampuan adsorpsi adsorben cangkang kerang bulu diuji dengan menggunakan larutan sampel $\mathrm{Cd}$ (II) dan $\mathrm{Pb}$ (II). Konsentrasi larutan sisa hasil adsorpsi diukur dengan AAS. Hasil penelitian menunjukkan bahwa luas permukaan adsorben yang diaktivasi pada suhu $110^{\circ} \mathrm{C}, 500^{\circ} \mathrm{C}$ dan $800^{\circ} \mathrm{C}$ sebesar 725,$43 ; 807,94$; dan $803,822 \mathrm{~m}^{2} / \mathrm{kg}$. Berat jenis berbanding terbalik dengan suhu aktivasi, nilai kadar air dan abu sesuai dengan nilai SNI yang ditetapkan. Adsorben yang diaktivasi pada suhu $500^{\circ} \mathrm{C}$ sesuai dengan persamaan Isoterm Freundlich.
\end{abstract}

Kata kunci: aktivasi termal, BET, Isoterm Freundlich

\begin{abstract}
Adsorbent from fur shells could be used to adsorb heavy metal ions such, as $\mathrm{Cd}$ (II) and $\mathrm{Pb}$ (II). This is shown by the research of adsorption using the fur shells. This research was aimed to characterize the fur shells. Variables in this research were the activation temperature and concentration of the metal solution. This research was begun with reduction of the shell size to 140 mesh, then thermal activation at temperature $110^{\circ} \mathrm{C}, 500^{\circ} \mathrm{C}$ and $800^{\circ} \mathrm{C}$ in the furnace. After that adsorbent was characterized using BET, measured its density, moisture content and ash, the adsorption capacity of the adsorbent was tested by using solution of $\mathrm{Cd}$ (II) and $\mathrm{Pb}$ (II), and then the concentration of the remaining solution was measured by AAS. The result showed that activated adsorbent at temperatures $110^{\circ} \mathrm{C}, 500^{\circ} \mathrm{C}$ and $800^{\circ} \mathrm{C}$ had surface area of 725.43; 807.94; and $803.822 \mathrm{~m}^{2} / \mathrm{g}$. Density was inversely proportional to the activation temperature, the value of moisture content and ash obtained were in accordance to SNI. Activated adsorbent at $500^{\circ} \mathrm{C}$ suitabled with the Freundlich Isotherm.
\end{abstract}

Key words: activation temperature, BET, Freundlich Isotherm

\section{Pendahuluan}

Saat ini ketertarikan akan sumbersumber bahan baku yang berasal dari limbah semakin meningkat. Sebagai contoh, cangkang hewan laut yang dapat digunakan sebagai bahan baku yang dapat dimanfaatkan kembali. Di negara maju seperti Jepang hewan laut seperti tiram digunakan kembali sebagai bahan baku pembuatan adsorben yang disebabkan cangkang tiram merupakan sumber kalsium [3].

Penelitian tentang menghilangkan senyawa toksik dari limbah air sering dilakukan oleh para peneliti. Proses pengendapan secara kimia dengan menggunakan alum $\mathrm{Al}(\mathrm{OH})_{3}$ dan feri oksida digunakan dalam level industri. Akan tetapi, senyawa yang beracun juga dihasilkan dan sulit untuk dilakukan penanganan terhadap limbah yang dihasilkan. Penghilangan senyawa toksik dengan adsorpsi merupakan metode yang menarik disebabkan ramah lingkungan serta pengoperasian yang mudah. Salah satu adsorben yang dapat digunakan adalah cangkang kerang yang banyak mengandung $\mathrm{CaCO}_{3}$. Kalsium karbonat merupakan bahan yang sesuai dalam penghilangan senyawa toksik seperti fosfat dan limbah logam 
dikarenakan $\mathrm{CaO}$ yang merupakan komponen pengaktif untuk pengadsorpsi senyawa beracun tersebut dapat dihasilkan dari senyawa $\mathrm{CaCO}_{3}[9]$.

Polusi lingkungan merupakan salah satu isu yang dihadapi kehidupan masyarakat. Dalam beberapa tahun belakangan ini semakin meningkat dan telah mencapai level yang membahayakan dalam kehidupan makhluk hidup. Sebagai contoh, pembuangan limbah industri yang mengandung timbal, tembaga, kadmium, dan kromium, dimana limbah tersebut dapat mengkontaminasi sumber air bawah tanah dan menyebabkan polusi yang sangat serius.

Dengan demikian, penelitan ini bertujuan untuk mencari alternatif bahan baku yaitu limbah cangkang kerang yang akan digunakan sebagai adsorben dalam hal penghilangan senyawa - senyawa logam yaitu $\mathrm{Pb}^{2+}$ dan $\mathrm{Cd}^{2+}$ yang dihasilkan oleh industri.

\section{Teori}

Produksi kerang - kerangan di Indonesia dari tahun 2002 ke tahun berikutnya semakin meningkat. Hal ini terlihat dari data produksi dari tahun 2002 sampai dengan 2006 secara berturut - turut, sebesar 7.00 ton, 12,86 ton, 12,99 ton, 16,35 ton dan 18,87 ton [5].

Pada cangkang kerang terdapat kandungan $\mathrm{CaCO}_{3}$ sebesar $95-99 \%$ berat. Sehingga sangat baik untuk dijadikan sebagai bahan baku adsorben. Dengan cara kalsinasi, maka akan dihasilkan senyawa pengaktif yaitu $\mathrm{CaO}$ [7]. Dengan rumus kimia sebagai berikut :

$$
\mathrm{CaCO}_{3}(\mathrm{~s}) \leftrightarrow \mathrm{CaO}(\mathrm{s})+\mathrm{CO}_{2}(\mathrm{~g})
$$

Proses karbonasi adalah proses yang bersifat reversibel dimana proses ini merupakan pengabuan zat. Menurut Martin (2008) karbonasi adalah proses pirolisis pada temperatur $400-900^{\circ} \mathrm{C}$, dimana tujuan karbonasi adalah untuk menghilangkan zat - zat yang mudah menguap (volatile matter) yang terkandung dalam bahan dasar [11]. Adapun reaksi karbonasi eksotermik sebagai berikut [8]: $\mathrm{CaO}(\mathrm{s})+\mathrm{CO}_{2}(\mathrm{~g}) \leftrightarrow \mathrm{CaCO}_{3}(\mathrm{~s})$

Sedangkan aktivasi menurut Martin (2008) adalah bagian dari proses pembuatan adsorben yang bertujuan untuk memperbesar ukuran dan distribusi pori serta memperluas permukaan adsorben dengan proses heat treatment pada temperatur $800-1200^{\circ} \mathrm{C}$
[11]. Adapun reaksi dari proses kalsinasi endotermik sebagai berikut [8]:

$\mathrm{CaCO}_{3}(\mathrm{~s}) \leftrightarrow \mathrm{CaO}(\mathrm{s})+\mathrm{CO}_{2}(\mathrm{~g})$

\section{Metodologi Penelitian}

Bahan yang digunakan pada penelitian ini adalah cangkang kerang bulu, Larutan logam $\mathrm{Cd}(\mathrm{II})$ dan $\mathrm{Pb}(\mathrm{II})$. Sedangkan peralatan utama yang digunakan adalah peralatan kaca yang terdapat di laboratorium, peralatan penguji yaitu BET, Spektofotometer Serapan Atom dan peralatan pendukung yaitu Ball Mill, Ayakan 140 mesh, serta desikator.

\section{Pembuatan Adsorben Cangkang Kerang Bulu}

Cangkang kerang bulu dicuci dengan air hingga bersih dan dikeringkan. Kemudian dihancurkan menjadi lebih kecil dengan lumpang dan alu serta digiling menjadi serbuk dengan ball mill. Serbuk tersebut diayak dengan ayakan yang berukuran 140 mesh. Hasil ayakan yang lolos dipanaskan pada suhu $110^{\circ} \mathrm{C}$ di oven, $500^{\circ} \mathrm{C}$ dan $800^{\circ} \mathrm{C}$ di furnace selama 4 jam. Setelah itu, hasil pemanasan dimasukan ke dalam desikator [7,14].

\section{Karakterisasi Adsorben Cangkang Kerang Bulu}

Hasil adsorben cangkang kerang bulu pada suhu $110^{\circ} \mathrm{C}, \quad 500^{\circ} \mathrm{C}$ dan $800^{\circ} \mathrm{C}$ kemudian diukur dengan menggunakan peralatan Analisa BET untuk mengetahui luas permukaan adsorben.

\section{Penentuan Jumlah Logam Cd(II) dan Pb(II) yang Terjerap Dalam Adsorben}

Dimasukkan 1 gram sampel cangkang kerang bulu pada suhu $110^{\circ} \mathrm{C}$ ke dalam beaker glass $100 \mathrm{ml}$, ditambahkan $50 \mathrm{ml}$ larutan logam $\mathrm{Cd}(\mathrm{II})$ atau $\mathrm{Pb}(\mathrm{II})$ dengan konsentrasi 60, 80, dan 100 ppm ke dalam beaker glass yang telah berisi sampel. Campuran diaduk dengan magnetic stirrer dengan putaran $200 \mathrm{rpm}$ suhu $25^{\circ} \mathrm{C}$. Hasil pengadukan disaring dengan menggunakan kertas saring. Filtrat diambil unuk diukur konsentrasi akhir $\mathrm{Cd}$ (II) dan $\mathrm{Pb}$ (II) dengan menggunakan Spektrofotometer Serapan Atom (SSA). Banyaknya $\mathrm{Cd}(\mathrm{II})$ dan $\mathrm{Pb}(\mathrm{II})$ yang terjerap oleh setiap gram sampel dapat dihitung dengan persamaan 1 sebaga berikut $[4,12]$ :

$$
\mathrm{W}=\frac{\mathrm{C}_{1}-\mathrm{C}_{2}}{1.000} \times \mathrm{V} \times \frac{1}{\mathrm{~B}} \cdots \cdots \cdots
$$


Keterangan :

\begin{tabular}{|l|l|l|}
\hline $\mathrm{W}$ & $=$ & $\begin{array}{l}\text { berat } \mathrm{Cd}(\mathrm{II}) \text { atau } \mathrm{Pb}(\mathrm{II}) \text { yang } \\
\text { terjerap oleh satu gram sampel } \\
(\mathrm{mg} / \mathrm{g})\end{array}$ \\
\hline $\mathrm{B}$ & $=\begin{array}{l}\text { berat adsorben yang digunakan } \\
(\mathrm{g})\end{array}$ \\
\hline $\mathrm{C}_{1}$ & $=$ & $\begin{array}{l}\text { konsentrasi larutan Cd(II) atau } \\
\mathrm{Pb}(\mathrm{II}) \text { awal (mg/l) }\end{array}$ \\
\hline $\mathrm{C}_{2}$ & $=$ & $\begin{array}{l}\text { konsentrasi larutan Cd(II) atau } \\
\mathrm{Pb}(\mathrm{II}) \text { akhir (mg/l) }\end{array}$ \\
\hline $\mathrm{V}$ & $=$ & $\begin{array}{l}\text { volume larutan Cd(II) atau } \\
\mathrm{Pb}(\mathrm{II}) \text { yang digunakan (ml) }\end{array}$ \\
\hline
\end{tabular}

Hasil

Aktivasi Adsorben Cangkang Kerang Bulu

Dari hasil pemanasan adsorben pada variasi suhu $110^{\circ} \mathrm{C}, \quad 500^{\circ} \mathrm{C}$ dan $800^{\circ} \mathrm{C}$ menghasilkan karakteristik adsorben yang berbeda - beda, hal ini terlihat dari segi warna dan bentuknya yang dihasilkan. Proses aktivasi ini dilakukan untuk memperbesar pori sehingga mampu menjerap senyawa - senyawa seperti $\mathrm{Cd}^{2+}$ dan $\mathrm{Pb}^{2+}$.

Adsorben yang dihasilkan pada suhu aktivasi $110^{\circ} \mathrm{C}$ memiliki karakterisitik dan warna yang sama dengan warna sebelum pemanasan, memiliki bentuk berupa butiranbutiran halus. Hal ini disebabkan belum terjadinya proses kalsinasi-karbonasi, serta belum terjadi perubahan komposisi sifat dari cangkang kerang, sehingga warna dari cangkang kerang itu sendiri masih sama dengan hasil sebelum pemanasan.

Adsorben yang dihasilkan pada suhu aktivasi $500^{\circ} \mathrm{C}$ memiliki karakteristik berwarna abu kehitaman dan berbeda dengan warna sebelum pemanasan. Setelah pemanasan didalam furnace adsorben mengeras/ membatu, dan setelah didinginkan strukturnya menjadi rapuh sehingga mudah untuk dipecahkan menjadi butiran - butiran halus.

Proses karbonasi adalah proses yang bersifat reversibel dimana proses ini merupakan pengabuan zat. Proses karbonasi dilakukan diantara suhu $400-900^{\circ} \mathrm{C}$ [11]. Adapun reaksi karbonasi eksotermik sebagai berikut [8]: $\mathrm{CaO}(\mathrm{s})+\mathrm{CO}_{2}(\mathrm{~g}) \leftrightarrow \mathrm{CaCO}_{3}(\mathrm{~s})$

Proses ini dilakukan pada suhu $500^{\circ} \mathrm{C}$, dimana cangkang kerang yang dihasilkan berwarna abu kehitaman. Kemudian luas permukaannya pun telah berbeda dari suhu sebelumnya yaitu $110^{\circ} \mathrm{C}$, hal ini dapat dilihat dalam analisa BET.
Adsorben yang diaktivasi pada suhu $800^{\circ} \mathrm{C}$ memiliki karakteristik berwarna putih mengkilap dan memiliki warna yang hampir sama dengan sebelum pemanasan.

Setelah proses pirolisa, adsorben mengeras / membatu. Kemudian dilakukan pendinginan dan strukturnya menjadi rapuh sehingga mudah dipecahkan menjadi butiran - butiran halus.

Proses kalsinasi pada cangkang kerang bulu adalah proses untuk memperbesar ukuran dan distribusi pori dan suhu proses dilaksanakan pada $800-1200^{\circ} \mathrm{C}$ [11]. Adapun reaksi dari proses kalsinasi endotermik sebagai berikut [8]:

$\mathrm{CaCO}_{3}(\mathrm{~s}) \leftrightarrow \mathrm{CaO}(\mathrm{s})+\mathrm{CO}_{2}(\mathrm{~g})$

Pada aktivasi cangkang kerang suhu $800^{\circ} \mathrm{C}$, telah terjadi proses kalsinasi, hal ini terlihat dari tidak adanya lagi warna adsorben yang bewarna kehitaman akibat pemanasan.

\section{Karakterisasi Adsorben Cangkang Kerang Bulu Dengan Peralatan BET}

Dalam penelitian ini, dilakukan analisa terhadap adsorben cangkang kerang bulu dari ketiga variasi suhu yaitu $110^{\circ} \mathrm{C}, 500^{\circ} \mathrm{C}$ dan $800^{\circ} \mathrm{C}$ menggunakan peralatan BET. Hal ini dilakukan untuk mengetahui luas permukaan masing - masing adsorben dari ketiga variasi suhu tersebut.

Tabel 1. Data Hasil Analisa BET

\begin{tabular}{|c|c|c|c|}
\hline \multirow{2}{*}{ Hasil } & \multicolumn{3}{|c|}{ Suhu $\left({ }^{\circ} \mathrm{C}\right)$} \\
\cline { 2 - 4 } & 110 & 500 & 800 \\
\hline $\mathrm{A}$ & 725,43 & 807,94 & 803,82 \\
\hline $\mathrm{V}$ & 1,803 & 2,041 & 1,995 \\
\hline $\mathrm{r}$ & 497,02 & 505,32 & 496,49 \\
\hline
\end{tabular}

Dari data tabel 1 diatas terlihat bahwa proses pengaktifan cangkang kerang bulu secara fisika menghasilkan perbedaan luas permukaan, volume pori, dan radius pori cangkang kerang yang berbeda antara satu dengan yang lain. Dimana dalam proses ini yang berperan adalah perbedaan suhu.

Menurut Rouquerol, et al (1998), untuk menjadi adsorben yang efektif, maka harus memiliki luas permukaan minimal $5 \mathrm{~m} 2 / \mathrm{g}$. Tetapi untuk menjadi adsorben yang komersil maka luas permukaannya, menurut Yang, (2003), sebesar $300-400 \mathrm{~m} 2 / \mathrm{g}$, sedangkan Bansal, et al., (2005) sebesar 800 - 1500 m2/g, dan Rouquerol, et al., (1998) sebesar $2000 \mathrm{~m} 2 / \mathrm{g}$ [11]. Dengan demikian, maka luas permukaan adsorben dari ketiga jenis suhu yaitu $110^{\circ} \mathrm{C}, 500^{\circ} \mathrm{C}$, dan $800^{\circ} \mathrm{C}$ telah memenuhi luas permukaan minimal 
untuk menjadi adsorben yang efektif dan komersil.

\section{Penentuan Berat Jenis dari Cangkang Kerang Bulu}

Dalam penelitian ini ditentukan berat jenis dari masing - masing adsorben yang telah diaktivasi suhunya sebesar $100^{\circ} \mathrm{C}$, $500^{\circ} \mathrm{C}$ dan $800^{\circ} \mathrm{C}$.

Tabel 2. Data Hasil Pengukuran Berat Jenis dari Adsorben

\begin{tabular}{|c|c|c|}
\hline No & Suhu $\left({ }^{\circ} \mathrm{C}\right)$ & Berat Jenis $(\mathrm{g} / \mathrm{ml})$ \\
\hline 1 & 110 & 2,96 \\
\hline 2 & 500 & 2,93 \\
\hline 3 & 800 & 2,68 \\
\hline
\end{tabular}

Pada tabel 2 diatas terlihat bahwa semakin tinggi suhu maka semakin rendah nilai densitas yang diperoleh. Hal ini disebabkan, aktivasi termal (fisika) bertujuan memperbesar volume pori seiring bertambahnya suhu.

Hal ini dapat dilihat dari analisa BET, pada Adsorben $110^{\circ} \mathrm{C}$ volume pori sebesar $1,803 \mathrm{cc} / \mathrm{g}$, ketika adsorben $500^{\circ} \mathrm{C}$ volume pori sebesar $2,041 \mathrm{cc} / \mathrm{g}$. Walaupun terjadi penurunan volume pori pada $800^{\circ} \mathrm{C}$ hal ini kemungkinan disebabkan kesalahan pengukuran pada proses degassing. Oleh karena itu, jika sesuai dengan persaman 2 [1]:

$$
\rho=\frac{\mathrm{m}}{\mathrm{v}} \quad \text { ….............. (2) }
$$

maka semakin besar volume akan memperkecil dari nilai berat jenis yang diperoleh. Sehingga hasil yang diperoleh telah sesuai dengan data yang ada.

\section{Penentuan Kadar Air}

Penentuan ini dilakukan untuk menentukan seberapa banyak air yang teruapkan sehingga air yang menutupi pori pada adsorben dapat dihilangkan. Hilangnya senyawa air yang terdapat pada pori - pori adsorben menyebabkan luas permukaan pori bertambah luas. Sehingga kemampuan adsorben dalam menjerap senyawa bertambah baik [10]. Diperoleh nilai \% penguapan kadar air dari masing - masing adsorben suhu $110^{\circ} \mathrm{C}, 500^{\circ} \mathrm{C}$ dan $800^{\circ} \mathrm{C}$ adalah $0,69 \%, 1,69 \%$, dan $1,71 \%$.

Berdasarkan kualitas yang diberikan oleh Lembaga Standar Nasional Indonesia (SNI) nomor 06-3730-1995 bahwa kadar air untuk arang aktif (karbon aktif) berbentuk serbuk maks 15\% [13]. Dengan demikian, hasil yang diperoleh pada masing
- masing adsorben cangkang kerang bulu masih sesuai dengan standar yang ditetapkan oleh SNI 06-3730-1995.

\section{Penentuan Kadar Abu}

Penentuan ini dilakukan untuk menentukan seberapa banyak mineral ataupun pengotor lainnya yang terdapat dalam adsorben. Pada adsorben terdapat lapisan monolayer yang membentuk pori yang biasanya terdapat mineral ataupun pengotor lainnya yang menutupi pori. Ketika terjadi proses aktivasi, pengotor pada lapisan tersebut akan menguap yang menyebabkan pori bertambah luas. Sehingga kemampuan adsorben menjerap senyawa akan semakin baik [10]. Diperoleh bahwa \% penguapan kadar abu dari masing - masing adsorben suhu $110^{\circ} \mathrm{C}, 500^{\circ} \mathrm{C}$ dan $800^{\circ} \mathrm{C}$ adalah $8,39 \%, 7,93 \%$, dan 7,86\%.

Berdasarkan kualitas yang diberikan oleh Lembaga Standar Nasional Indonesia (SNI) nomor 06 - 3730 - 1995 bahwa kadar abu untuk arang aktif (karbon aktif) berbentuk serbuk maks $10 \%$ [13]. Dengan demikian, hasil yang diperoleh pada masing - masing adsorben cangkang kerang bulu masih sesuai dengan standar yang ditetapkan oleh SNI 06-3730-1995.

\section{Penentuan Jumlah Logam Cd(II) dan Pb (II) yang Terjerap oleh Adsorben}

Pada penelitian ini, digunakan adsorben hasil aktivasi pada suhu $500^{\circ} \mathrm{C}$ untuk menjerap larutan Cd(II) dan Larutan $\mathrm{Pb}(\mathrm{II})$.

Semakin besar konsentrasi larutan, semakin banyak jumlah zat terlarut yang dapat diadsorpsi sehingga tercapai keseimbangan tertentu, dimana laju zat yang dijerap sama dengan zat yang dilepas dari adsorben pada suhu tertentu [6]. Untuk menentukan \% penjerapan terhadap logam $\mathrm{Cd}^{2+}$ dan $\mathrm{Pb}^{2+}$ digunakan persamaan 3 sebagai berikut [14] :

$\%$ penjerapan $=\frac{C o-C}{C o} \times 100 \%$

Tabel 3. Data Hasil Persentase Penjerapan Logam $\mathbf{C d}^{2+}$ dan $\mathbf{P b}^{2+}$

\begin{tabular}{|l|l|l|c|}
\hline No & \multirow{2}{*}{$\begin{array}{c}\text { Konsentrasi } \\
\text { Awal }\end{array}$} & \multirow{2}{|c|}{ Persentase Penjerapan } \\
\cline { 3 - 4 } & $(\mathrm{ppm})$ & \multicolumn{1}{|c|}{$\mathrm{Cd}^{2+}$} & $\mathrm{Pb}^{2+}$ \\
\hline 1 & 60 & $99,38 \%$ & $99,98 \%$ \\
\hline 2 & 80 & $99 \%$ & $99,96 \%$ \\
\hline 3 & 100 & $98,91 \%$ & $99,88 \%$ \\
\hline
\end{tabular}


Dari tabel 3 diatas dapat dikatakan bahwa adsorben cangkang kerang pada suhu aktivasi $500^{\circ} \mathrm{C}$ sangat baik dalam menjerap logam $\mathrm{Cd}^{2+}$ dan $\mathrm{Pb}^{2+}$

Penentuan Adsorpsi Isoterm Cd(II) dan $\mathrm{Pb}$ (II) yang Terjerap oleh Adsorben

\section{A. Isoterm Freundlich}

Untuk menentukan Isoterm freundlich dari adsorpsi logam $\mathrm{Cd}(\mathrm{II})$ dan $\mathrm{Pb}(\mathrm{II})$ maka digunakan persamaan 4 dibawah yaitu [2]:

$$
\mathrm{q}=K C^{n}
$$

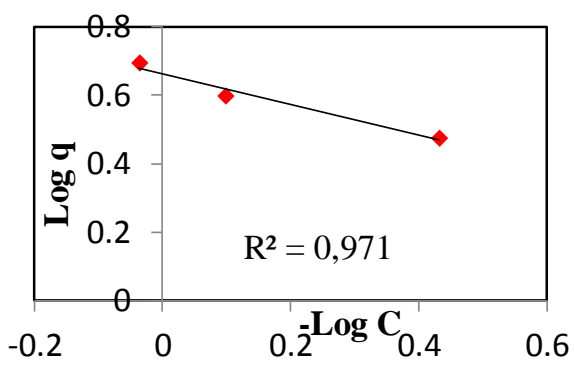

Gambar 1. Data Hasil Adsorpsi Isoterm Freundlich Adsorben terhadap $\mathrm{Cd}^{2+}$

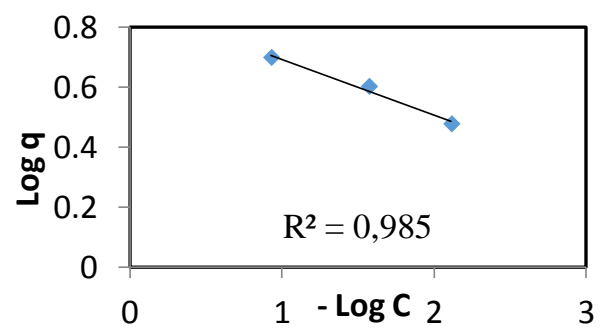

Gambar 2. Data Hasil Adsorpsi Isoterm Freundlich Adsorben terhadap $\mathbf{P b}^{2+}$

Tabel 4. Nilai Isoterm Freundlich $\mathrm{Cd}^{2+}$ dan $\mathbf{P b}^{2+}$

\begin{tabular}{|c|c|c|}
\hline Isoterm & Nilai & $\mathrm{Y}=$ \\
\hline $\begin{array}{c}\text { Freundlich } \\
\mathrm{Cd}^{2+}\end{array}$ & $\mathrm{n}=-0,45$ & $-0,450 \mathrm{x}+0,662$ \\
\hline & $\mathrm{K}=4,59$ & \\
\hline $\begin{array}{c}\text { Freundlich } \\
\mathrm{Pb}^{2+}\end{array}$ & $\mathrm{n}=-0,185$ & $-0,185 \mathrm{x}+0,878$ \\
\hline & $\mathrm{K}=7,5$ & \\
\hline
\end{tabular}

Dari data tabel 4 terlihat nilai koefisien regresi untuk Isoterm Freundlich. Model persamaan Freundlich mengasumsikan bahwa terdapat lebih dari satu lapisan permukaan (multilayer) dan sisi bersifat heterogen, yaitu adanya perbedaan energi pengikat pada tiap-tiap sisi sedangkan persamaan adsorpsi Langmuir dilakukan terhadap lapisan tunggal zat yang teradsorpsi dari ion logam $\mathrm{Cd}^{2+}$ dan $\mathrm{Pb}^{2+}$ pada setiap permukaan adsorben dalam satuan $\mathrm{mg}$ ion logam yang teradsorp/gram adsorben [6].

Dengan nilai regresi tersebut, maka adsorben ini lebih sesuai dengan persamaan Isoterm Freundlich.

\section{Kesimpulan}

Adapun kesimpulan yang dapat diperoleh dari penelitian ini adalah:

1. Hasil analisa dengan peralatan BET menunjukkan luas permukaan dari adsorben yang diaktivasi pada suhu $500^{\circ} \mathrm{C}$ diperoleh sebesar $807,94 \mathrm{~m}^{2} / \mathrm{kg}$.

2. Nilai luas permukaan terbesar diperoleh pada suhu aktivasi $500^{\circ} \mathrm{C}$ dengan ukuran adsorben 140 mesh.

3. Semakin tinggi suhu aktivasi termal cangkang kerang maka nilai densitas adsorben yang diperoleh semakin menurun.

4. Hasil analisa kadar air menunjukkan semakin tinggi suhu aktivasi termal cangkang kerang maka semakin kecil nilai kadar air yang terdapat dalam cangkang kerang.

5. Hasil analisa kadar abu menunjukkan semakin tinggi suhu aktivasi termal cangkang kerang maka nilai persentase kadar abu yang diperoleh semakin menurun

Dengan demikian, adsorben cangkang kerang bulu yang dibuat secara fisis sudah dapat memenuhi adsorben yang efektif dan komersil, terlebih adsorben dengan suhu $500^{\circ} \mathrm{C}$ menunjukkan hasil karakterisasi yang dominan diantara adsorben dengan suhu aktivasi $110^{\circ} \mathrm{C}$ dan $800^{\circ} \mathrm{C}$ lainnya.

\section{Keterangan Notasi:}

$\begin{array}{rll}\text { Notasi } & \text { Keterangan } & \\ \mathrm{A} & =\text { Luas Permukaan } & \left(\mathrm{m}^{2} / \mathrm{g}\right) \\ \mathrm{V} & =\text { Volume } & (\mathrm{cc} / \mathrm{g}) \\ \mathrm{r} & =\text { Jari }- \text { jari } & (\mathrm{A}) \\ \rho & =\text { Densitas } & (\mathrm{g} / \mathrm{ml}) \\ \mathrm{m} & =\text { Massa } & (\mathrm{G}) \\ \mathrm{Co} & =\text { Konsentrasi awal } & (\mathrm{ppm}) \\ \mathrm{C} & =\text { Konsentrasi akhir } & (\mathrm{ppm})\end{array}$




\section{Daftar Pustaka}

[1] David Hugh Young, Roger A. Freedman, Sears and Zemansky's University Physics, New York, Addison-wesley, (2000). Hal 10.

[2] Geankoplis, C.J. Transport Process and Unit Operation, New York, Allyn and Bacon, (2003). Hal 697 701.

[3] Hiroaki Onoda, Hironari Nakanishi, Preparation of Calcium Phospate With Oyster Shells, Journal scientific Research, 3, 71 - 74, (2012).

[4] Jasinda, Skripsi, Pembuatan dan Karakterisasi Adsorben Cangkang Telur Bebek yang Diaktivasi Secara Termal, Program Sarjana Fakultas Teknik USU, Medan, (2013).

[5] Muntamah, Tesis, Sintesis dan Karakterisasi Hidroksiapatit dari Limbah Cangkang Kerang Darah, Program PascaSarjana Fakultas Pertanian IPB, Bogor, (2011). Hal 16

[6] Murni Handayani, Eko Sulistiyono, Uji Persamaan Langmuir dan Freundlich pada Penyerapan Limbah Chrom (VI) oleh Zeolit, Prosiding Seminar Nasional Sains dan Teknologi Nuklir, Pusat Penelitian Metalurgi-LIPI, (2009). Hal 134.

[7] Mustakimah Mohamed, Suzana Yusup, Saikat Maitra, Decomposition Study of Calcium Carbonate in Cockle Shell, Journal of Engineering science and Tecnology, Vol 7, No. 1, (2012).

[8] Nor Adilla Rashidi, M. Mohamed, S.Yusup, The Kinetic Model of Calcination And Carbonation of Anadara Granosa, Department of Chemical Engineering, Universiti Teknologi Petronas, Internasional Journal of Renewable Energy Research, (2012).

[9] Ratanapom. Y, Duangkamol $\mathrm{Na}$ Ranong, Recycling Osyter Shell as Adsorbent for Phosphate Removal, The 21st Thai Institute of Chemical Engineering and Applied Chemistry, (2011). Diakses 27 Oktober 2013.

[10] Rosita Idrus, Boni Pahlanop Lapanporo, Yoga Satria Putra, Pengaruh Suhu Aktivasi terhadap Kualitas Karbon Aktif Berbahan Dasar Tempurung Kelapa, Prisma Fisika, Vol 1, No. 1, (2013). Hal 50 -55 .
[11] Ryan Hendra, Skripsi, Pembuatan Karbon Aktif Berbahan Dasar Batubara Indonesia dengan Metode Aktivasi Fisika dan Karakteristiknya, Program Sarjana Fakultas Teknik UI, Jakarta, (2008). Hal 29.

[12] Stevens A Odoemelam, Nnabuk Okon Eddy, Studies on the Use of Oyster, Snail and Periwinkle Shells as Adsorbents for the Removal of $\mathrm{Pb}$ 2+ from Aqueous Solution, E J.Chem, 6(1), 213 - 222, (2009).

[13] Sudrajat, R. Gustan Pari, Arang Aktif Teknologi Pengolahan dan Masa Depannya, Jakarta, Badan Penelitian dan Pengembangan Kehutanan, (2012). Hal.29.

[14] Yong Sik Ok, dkk, Effect of Natural and Calcined Oyster Shells on Cd and $\mathrm{Pb}$ Immobilization in Contaminated Soils, Journal of Environment Earth Sciences, 61, $1301-1308$, (2010). 